Cecilia E. Enriquez • Georgy I. Shapiro

Alejandro J. Souza $\cdot$ Andrei G. Zatsepin

\title{
Hydrodynamic modelling of mesoscale eddies in the Black Sea
}

Received: 17 March 2005/ Accepted: 15 August 2005/Published online: 13 October 2005

(C) Springer-Verlag 2005

\begin{abstract}
A three dimensional structure of mesoscale circulation in the Black Sea is simulated using the Proudman Oceanographic Laboratory Coastal Ocean Modelling System. A number of sensitivity tests reveal the response of the model to changes in the horizontal resolution, time steps, and diffusion coefficients. Three numerical grids are examined with $x$-fine $(3.2 \mathrm{~km})$, fine $(6.7 \mathrm{~km})$ and coarse $(25 \mathrm{~km})$ resolution. It is found that the coarse grid significantly overestimates the energy of the currents and is not adequate even for the study of basin-scale circulation. The $x$-fine grid, on the other hand, does not give significant advantages compared to the fine grid, and the latter is used for the bulk of simulations. The most adequate parameters are chosen from the sensitivity study and used to model both the basin-scale circulation and day-to-day variability of mesoscale currents for the months of May and June of 2000. The model is forced with actual wind data every $6 \mathrm{~h}$ and monthly climatic data for evaporation, precipitation, heat fluxes and river run-off. The results of the fine grid model are compared favourably against the satellite imagery. The model adequately reproduces the general circulation and many mesoscale features including cyclonic and anticyclonic eddies, jets and filaments in different parts of the Black Sea. The model gives a realistic geographical distribution and parame-
\end{abstract}

Responsible Editor: Paulo Salles

C. E. Enriquez · G. I. Shapiro $(\bowtie)$

School of Earth, Ocean and Environmental Sciences,

University of Plymouth, Drake Circus, Plymouth,

Devon, PL4 8AA United Kingdom

E-mail: gshapiro@plymouth.ac.uk

Tel.: + 44-1752-233423

Fax: + 44-1752-232406

\section{A. J. Souza}

Proudman Oceanographic Laboratory, 6 Brownlow Street, Liverpool, L3 5DA United Kingdom

A. G. Zatsepin

P.P. Shirshov Institute of Oceanology, 36, NakhimovskyProspekt, 117997 Moscow, Russia ters of mesoscale currents, such as size, shape and evolution of the eddies.

Keywords Modelling $\cdot$ Eddies $\cdot$ Black Sea $\cdot$ Mesoscale

\section{Introduction}

Mesoscale circulation plays a significant role in forming the general circulation all around the ocean (Wilson and Williams 2004). Mesoscale eddies and meanders have spatial and temporal scales which allow them to act also as a link between the coastal environment and the open ocean (Huthnance 1995; Shapiro et al. 2000). As such they can provide a mechanism of transport of nutrient rich material from the coastal zone to the oligotrophic and unproductive deep sea environment. Mesoscale circulation is thought to play an important role in forming the horizontal transports in the Black Sea (Zatsepin et al. 2003).

The Black Sea (Fig. 1) is an enclosed basin with only one connection to the open ocean through a narrow and shallow channel, the Bosphorus Strait. Its ecosystem is confronted with many environmental problems (Mee 2001), which influence marine habitats and communities. Excessive amounts of nutrients are discharged into the coastal zone by local rivers, and gradually disperse over larger areas of the sea.

The realistic basin-scale surface circulation pattern of Black Sea waters, based on hydrological observations was first compiled by Knipovich (Knipovich 1932). It includes a basin-scale boundary Rim Current with velocities of up to $1 \mathrm{~m} / \mathrm{s}$ and a few semi-permanent cyclonic gyres in the deep part of the sea. Although there are some arguments on the number (2, 3 or more) of semi-permanent sub-gyres, it is definitely confirmed that the cyclonical general circulation is the basic feature of the Black Sea dynamics and is typical for all seasons of the year. However, this traditional view was not able to explain the variety of exchange processes in the Black 
Fig. 1 Map of the Black Sea showing the rivers and the bottom topography (m) used in this study. The high resolution bottom topography was smoothed and restricted to $1,500 \mathrm{~m}$ depth

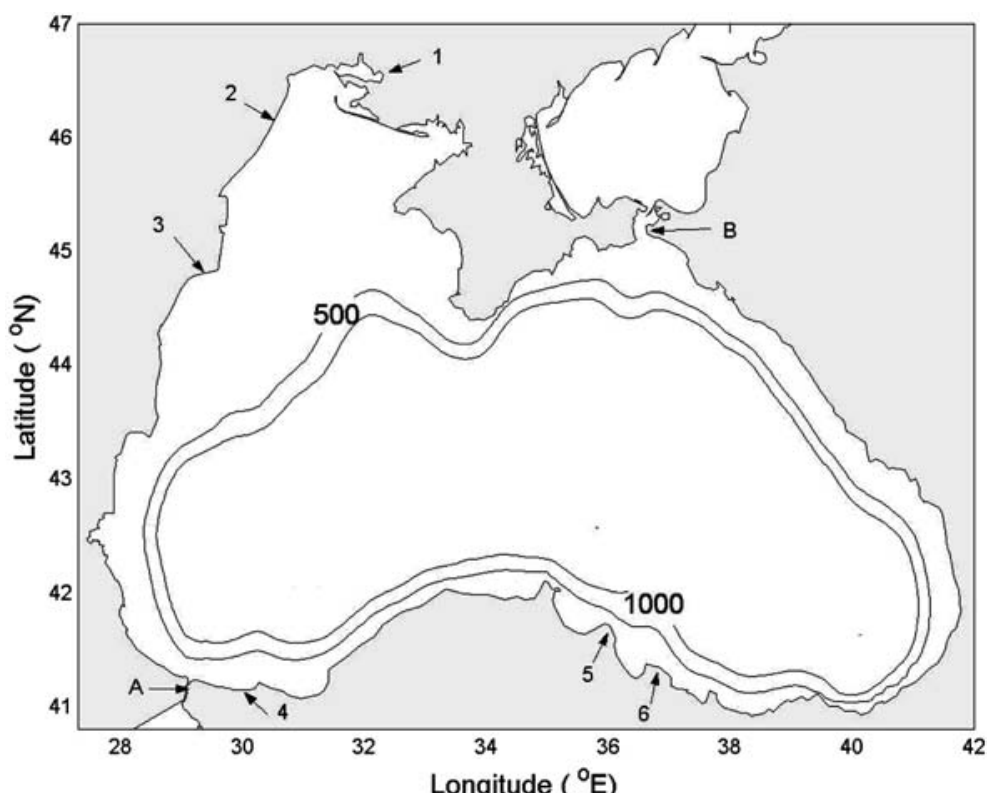

Sea and the formation of nearly homogeneous water mass in the upper layer, for e.g. see Blatov et al. 1984.

Recent studies have revealed strong mesoscale activity, which is thought to be a major contributor to the horizontal exchanges in the Black Sea. The evidence is supported by satellite data analysis of Sea Surface Temperature (Sur and Ilyin 1997; Ginzburg et al. 2000; Zatsepin et al. 2002) and chlorophyll (e.g. Vostokov et al. 2002), results of quasi-synoptic surveys (e.g. Oguz and Besiktepe 1999; Zatsepin et al. 2002), and numerical modelling (e.g. Stanev and Staneva 2001).

Mesoscale circulation in the Black Sea is represented by meanders of the basin-scale current, filaments, cyclonic and anticyclonic mesoscale eddies off-shore of the Rim Current. There are also Coastal Anticyclonic Eddies between the Rim Current and the coastline, which are sometimes smaller than offshore eddies. Mesoscale eddies have diameters normally of about $80-100 \mathrm{~km}$ and may penetrate into the pycnocline as deep as $300-400 \mathrm{~m}$. Their typical orbital velocity near the sea surface is about $0.15-0.50 \mathrm{~m} / \mathrm{s}$ (Zatsepin et al. 2003).

The increased resolution of recent oceanographic surveys, experiments with ARGOS-tracked drifters and the availability of satellite data has revealed that the Rim Current is not a permanent barrier inhibiting the water exchange between the coast and open sea (Zatsepin et al. 2003; Zhurbas et al. 2004); it may under specific circumstances become unstable at some locations allowing horizontal mixing.

Despite the increasing availability of the studies based on in situ and remote sensed measurements in the Black Sea, our understanding of the three-dimensional dynamics and fluxes has been significantly increased by using numerical models. Several attempts have been tried using different numerical models, amongst others the Bryan-Cox primitive equation model (e.g. Stanev et al. 1995), the GeoHydrodynamics and Environment
Research-GHER-3D (Stanev and Beckers 1999), the Dietrich Center for Air Sea Technology-DieCAST (Staneva et al. 2001), the Princeton Ocean Model - POM (Oguz et al. 1995), the GFDL Modular Ocean Model (MOM) model (Stanev et al. 2005), which is a later version of the Bryan-Cox model and the Harvard Ocean Prediction System (HOPS) (Besiktepe et al. 2001).

Stanev et al. 1995 studied the response of the basinscale circulation to atmospheric forces using a relatively low resolution $\left(1^{\circ}\right)$ rigid lid model. Further progress, particularly in examining low frequency oscillations, was achieved by using free-surface models (Stanev and Beckers 1999). Reduced gravity models with altimeter data assimilation (Korotaev et al. 2003) allowed improving the forecast of large-scale currents. Inaccuracies introduced by $z$-coordinate models were partly cured by setting up the sigma-coordinate models for the Black Sea (Oguz et al. 1995, Stanev et al. 2005, Besiktepe et al. 2001). Many of these studies targeted processes other than mesoscale phenomena, sometimes because they were too coarse or very diffusive, leaving only few numerical studies appropriate for the mesoscale circulation.

The focus of this paper is to characterise mesoscale currents in the Black Sea, in particular, on the shelf and near the shelf break. While there is no such thing as a perfect model for this kind of studies, we have chosen the Proudman Oceanographic Laboratory Coastal Ocean Modelling System (POLCOMS) as a basis to investigate the mesoscale hydrodynamics of the Black Sea. Our specific objective was to implement the model so that it realistically represents both large scale circulation and mesoscale eddies in the Black Sea in terms of their size, location and speeds, examine the sensitivity of the model and identify the optimal set of model parameters. The POLCOMS has a number of advanced features, which should allow to accurately represent sharp fronts, particularly at the shelf break. However, 
the POLCOMS was developed and used mostly for the shelf sea areas such as the European shelf or the Irish Sea (Proctor et al. 2003). The purpose of this study was to examine if the model is capable of reproducing hydrodynamics in a setting, which combines both wide and narrow shelves as well as extensive areas of deep waters.

The details of the model set up and the analysis of the sensitivity tests are presented in Sect. 2. Section 3 describes the procedures used to spin up the model circulation as well as the data sets, which are used to drive the model. Analysis of mesoscale and basin-scale circulation is given in Sect. 4, which also includes discussions on model validation and comparison with observational data and previous numerical simulations. The paper ends with the conclusions in Sect. 5.

\section{Model set up and sensitivity tests}

At the centre of POLCOMS [http://www.pol.ac.uk/ home/research/polcoms/] there is a three-dimensional baroclinic model which takes its origin in the frontresolving model of James (1986). The main difference with other models is that POLCOMS is formulated on an Arakawa B grid (Arakawa 1972), in contrast to the C grid used in many other shelf seas models, for example, the Princeton Ocean Model (POM) (Blumberg and Mellor 1987); the Regional Ocean Modelling System (ROMS) (Haidvogel et al. 2000). The B grid, although more commonly used in deep ocean models is better suited to the modelling of horizontal density variations since the Coriolis term can be calculated without averaging. This prevents the dispersion of velocity features associated with fronts and eddies, in contrast with the $\mathrm{C}$ grid which requires averaging over a number of points to calculate this term. Another important difference of POLCOMS is that it uses the "Piecewise Parabolic Method" for advection. This high-order scheme is one of the least diffusive advective methods used in numerical models (James 1996) and even less diffusive than the more commonly used "Total Variation Diminishing" (TVD) (e.g. Souza and James 1996; Burchard and Bolding 2002).

Another characteristic of the model is the use of a refinement of the sigma-coordinate scheme which allows higher resolution in the vertical at particular areas of interest ( $s$-coordinate system). Since the model domain includes regions of steep topography, the traditional method of calculating pressure (or density) gradients along the sigma levels and then correcting it for the slope coordinates introduces a source of error which is well documented (e.g. Mellor et al. 1994; Shchepetkin and McWilliams 2003): in the case of a flat thermocline overlying steep topography, both these terms are of the same magnitude and should cancel; however, this generally leads to a large truncation error, which can drive erroneous currents.

A number of methods of overcoming this problem have been suggested (e.g. Shchepetkin and McWilliams
2003); in this paper, we follow the approach by Holt and James (2001), which involves estimating the four pressure gradients at the edges of the horizontal plane with $(u, v)_{\mathrm{i}, \mathrm{j}, \mathrm{k}}$ defined at the centre and the corners being at the $b$ columns $(i, j),(i-1, j),(i-1, j-1)$ and $(i, j-1)$; for simplicity we will use the subindex $q=1, \ldots, 4$, and we will drop the vertical index for $u$. So that the depth of the plane is

$z=\frac{1}{4}\left(\sigma \sum_{q} H_{\mathrm{q}}+\sum_{q} \zeta_{\mathrm{q}}\right)$

and at $b$ column, $q$, this is at $\sigma_{\mathrm{q}}=\left(\mathrm{z}-\zeta_{\mathrm{q}}\right) / \mathrm{H}_{\mathrm{q}}$. Here $\mathrm{H}$ is the depth of water and $\zeta$ is the sea level elevation. The nearest levels, $k_{q}$, above the plane lie at a fraction distance, $r=\left(\sigma_{k q}-\sigma_{q}\right) /\left(\sigma_{k q}-\sigma_{k q-1}\right)$, from the plane. If the buoyancy $\left(b_{\mathrm{q}, \mathrm{kq}}\right)$ is taken to vary linearly between $\sigma$ levels (each level separated by $\delta \sigma$ ), the pressure due to this interval can be estimated, and the pressure at $\sigma_{\mathrm{q}}$ can be written as:

$$
\begin{aligned}
\psi_{\mathrm{q}}= & -0.5 \psi \sigma\left[b_{q, N-2}+\sum_{k=k q}^{N-2}\left(b_{q, k q}+b_{q, q k+1}\right)\right. \\
& \left.+\left(2 r-r^{2}\right) b_{q, k q}+r^{2} b_{q, k q-1}\right]
\end{aligned}
$$

for $1 \leq k_{\mathrm{q}} \leq N-2$ and

$$
\psi_{q}=-0.5 \psi \sigma\left[\left(2 r-r^{2}\right) b_{q, k q}+r^{2} b_{q, k q-1}\right],
$$

for $\mathrm{k}_{\mathrm{q}}=\mathrm{N}-1$; in this calculation, level $\mathrm{k}=\mathrm{N}-1$ is at the seas surface, where buoyancy is defined by $b_{\mathrm{q}, \mathrm{N}-1}=$ $b_{0 \mathrm{q}, \mathrm{N}-2}$, where $b_{0 \mathrm{q}, \mathrm{N}-2}$ is the potential buoyancy.

The pressure gradients along the edges of the plane are then

$$
\begin{aligned}
& \Delta \psi_{1}=\psi_{1}-\psi_{2}, \quad \Delta \psi_{2}=\psi_{2}-\psi_{3}, \quad \Delta \psi_{3}=\psi_{4}-\psi_{3}, \\
& \Delta \psi_{4}=\psi_{1}-\psi_{4} .
\end{aligned}
$$

This technique allows a straightforward treatment of cases where the sea bed lies above the plane at one or more of the surrounding $b$ point; if the corners on an edge are below the sea level, then the corresponding pressure gradient takes the last defined value above it. Although we have described for simplicity, the case where the density varies linearly between $\sigma$, in practice we have used cubic splines to calculate $\psi_{q}$ which is an improvement from Holt and James (2001).

This method has been tested against pressure gradients given by analytically defined thermocline and gives significantly more accurate results than the conventional method. The combination of the grid and the advection scheme allows a better representation of mesoscale baroclinic features such as fronts and eddies. The model is formulated in spherical polar sigma coordinates. It solves the incompressible, hydrostatic, Boussinesq equations of motion and allows time splitting between barotropic and baroclinic components. 
The model domain (Fig. 1) ranges from 41 to $46.7^{\circ} \mathrm{N}$ and from 28 to $42^{\circ} \mathrm{E}$, covering the whole Black Sea basin except the areas with less than $10 \mathrm{~m}$ depth. The main grid has a horizontal resolution of $1 / 12^{\circ}$ in longitudinal direction and $1 / 16^{\circ}$ in latitudinal direction, which corresponds to about $6.5 \mathrm{~km}$ in both directions. The mesh has 92 latitudinal grid points, 168 longitudinal grid points and 24 vertical $s$-coordinate levels. The $s$-coordinate system allows high resolution in specific regions while mapping the varying topography (Song and Haidvogel 1994). For this study, the parameters are chosen to give greater resolution at the surface and at the bottom of the water column at each point (Fig. 2). The bottom topography was acquired from the ETOPO5 database (NOAA 1988), filtered out and cut to a maximum depth of $1,500 \mathrm{~m}$ in order to relax the CourantFriedrichs-Levy condition and to allow the use of a longer barotropic time step.

As any numerical model would produce only an approximate solution to the real problem, the results are usually dependent on a number of model parameters, such as grid size, integration time step, diffusivity coefficients, etc., (Kantha and Clayson 2000). A series of sensitivity tests were carried out to ensure an adequate model performance before running the main hydrodynamic simulations. The following model parameters were tested: (a) various versions of bottom topography (not included in this paper), (b) grid resolution, (c) baroclinic time step, (d) barotropic time step and (e) horizontal diffusion coefficient. The details of the numerical values used for sensitivity tests are given in Table 1.

The sensitivity analysis is particularly useful as the numerical code is technically stable even if it produces spurious results due to a wrong combination of numerical parameters. Sensitivity analysis allows us to identify spurious results at a very early stage. All the sensitivity tests start from a state of rest (zero velocities) and climatologic temperature and salinity distributions (Staneva and Stanev 1998). No external forcing is applied throughout this series of runs. In addition to the main ('fine resolution') grid $(92 \times 168 \times 24$ nodes $)$, the sensitivity tests were run on a 'coarse' grid $(24 \times 44 \times 24$ nodes) and an ' $x$-fine' grid $(183 \times 335 \times 24)$ and details on the different grids are listed in Table 2 . The model was found to be unstable when run on the original ETOPO5 bottom topography (these runs were carried out by Miss Clare O'Neill). The possible reason for this was the presence of a number of small steep canyons in the southern area of the sea featuring a narrow continental shelf. Small amount of smoothing rectified the problem and was assumed not to influence the mesoscale eddies in this area which have a horizontal scale (from observations) of a $100 \mathrm{~km}$. A posteriori comparison of model runs with satellite imagery confirmed this assumption (see Sect.4 for details). The results from both fine and coarse grid simulations are strongly dependent on the baroclinic time step but nearly independent of reasonable variations of the barotropic time step.

In experiments with the fine grid, the mean kinetic energy, MKE, reaches saturation much faster than with the coarse grid, about 5 or 6 days with the fine and 19 days with the coarse grid (see Fig 3a), and maintains an approximate equilibrium thereafter. The higher frequency component of the kinetic energy (i.e. eddy kinetic energy, EKE) is generated by the process of adjustment of velocity fields to initial density distribution and is mostly represented, for all three mesh sizes, by oscillations with a period of about $17 \mathrm{~h}$ (this corresponds to the inertial frequency for the Black Sea). The amplitude of energy oscillations decays with time as seen in Fig. 3b. We have noticed that the coarse grid simulations overestimate the current velocities in some areas and hence the kinetic energy evaluated with the coarse
Fig. 2 Zonal transect through the Black Sea at $44^{\circ} \mathrm{N}$ showing the $s$-coordinate surfaces

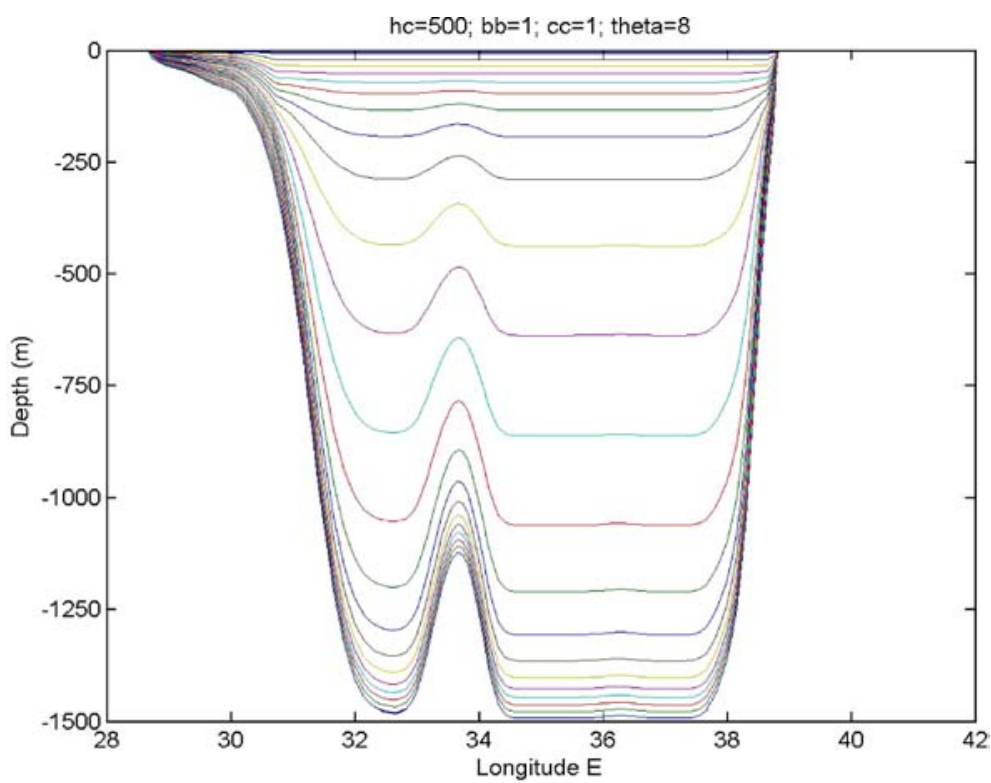


Table 1 Numerical experiments for sensitivity tests

\begin{tabular}{lllll}
\hline Run no & Grid & $\begin{array}{l}\text { Barotropic } \\
\text { time step (s) }\end{array}$ & $\begin{array}{l}\text { Baroclinic } \\
\text { time step (s) }\end{array}$ & $\begin{array}{l}\text { Run length } \\
\text { (days) }\end{array}$ \\
\hline 1 & Coarse & 20 & 200 & 30 \\
2 & Coarse & 20 & 400 & 30 \\
3 & Coarse & 20 & 600 & 30 \\
4 & Coarse & 20 & 800 & 30 \\
5 & Coarse & 10 & 400 & 30 \\
6 & Coarse & 40 & 400 & 30 \\
7 & Fine & 20 & 400 & 30 \\
8 & Fine & 20 & 300 & 30 \\
9 & Fine & 20 & 200 & 30 \\
10 & Fine & 10 & 200 & 30 \\
11 & X-fine & 5 & 25 & 8 \\
\hline
\end{tabular}

Table 2 Space discretisation of the different grids

\begin{tabular}{lllll}
\hline Grid & $\begin{array}{l}\text { Latitudinal resolution } \\
\text { (degrees) }\end{array}$ & $\begin{array}{l}\text { Longitudinal resolution } \\
\text { (degrees) }\end{array}$ & $\begin{array}{l}\text { Approximate } \\
\text { distance }(\mathrm{km})\end{array}$ & $\begin{array}{l}\text { Total no. of wet } \\
\text { grid points }\end{array}$ \\
\hline Coarse & $1 / 4$ & $1 / 3$ & $\sim 25.5$ & 12,048 \\
Fine & $1 / 16$ & $1 / 12$ & $\sim 6.7$ & 194,040 \\
X-fine & $1 / 31$ & $1 / 24$ & $\sim 3.4$ & 790,752 \\
\hline
\end{tabular}

grid is significantly greater than that of the fine grid. This result is opposite to the results obtained by (Stanev and Staneva 2000), who used a $z$-coordinate BryanSemtner-Cox modular ocean model, MOM, which underestimates the current velocities as the horizontal resolution gets coarser. This difference is probably introduced by different ways of discretisation in the vertical by the MOM and POLCOMS numerical schemes. It might also be due to the pressure gradient effect of the sigma coordinates in POLCOMS even when using the interpolation technique to reduce it.

Using the fine grid with the appropriate time steps (20 s barotropic and $200 \mathrm{~s}$ baroclinic) the model produces the level of kinetic energy, which is consistent with observations (e.g. Ozsoy and Unluata 1997; Zhurbas et al. 2004).

Experiments 2, 9 and 11 (Table 1) were used to find the effects of the grid resolution on the hydrodynamic results. The evolution of the basin averaged kinetic energy produced by using each of the three grids is shown in Figs. 3a,b. As there is no external forcing in this set of experiments, it is expected that kinetic energy will reach an equilibrium level within a time interval, which is consistent with the purpose of modelling, i.e. shorter than a typical mesoscale period-normally a few days. In case of the coarse grid, the kinetic energy reaches an equilibrium state only after 19 days of simulation, while saturation is clearly achieved in case of the fine and extra-fine grids within few days. Further experiments with full forcing on the coarse grid show that the increase of the horizontal diffusion does not solve the problem as it results in unrealistic widening of the Rim Current and over-damping of eddies. The conclusion is that the coarse grid would not be suitable for the study of both mesoscale (due to long response time) and basin-scale (due to overestimation of current velocities) circulations. The accuracy of modelling of the current velocities is significantly improved when switching from the coarse to the fine grid but little improvement (in terms of both basin-scale and mesoscale circulation) is observed when changing the fine grid for the $x$-fine one. Experiments with full forcing are also supportive of this conclusion. While not giving a noticeable improvement in accuracy, the $x$-fine grid is more expensive (by a factor of 16) in terms of computational time. Therefore, the fine grid with approximately $6.7 \mathrm{~km}$ resolution is chosen for this study.

Additional tests were performed to assess the sensitivity of the model to the horizontal diffusion coefficient, $A_{\mathrm{H}}$, which in this implementation is calculated as a function of water depth. The model does not use horizontal diffusion in the shallow water to a bathymetric depth, $H_{\text {crit }}$ of $200 \mathrm{~m}$. At deeper waters than $H_{\text {crit }}, A_{\mathrm{H}}$ is taken to be the minimum value between a prescribed critical value, $A_{\mathrm{HM}}$, and the product of a prescribed constant, $C_{\mathrm{A}}$, and the depth of water, $H$, at each grid point. The analysis shows that the sensitivity of the model to changes in the horizontal diffusion coefficient is small, with slightly slower and wider currents at higher values of $C_{\mathrm{A}}$. The best resemblance to the real Black Sea currents in terms of typical velocities and scale of the Rim Current and mesoscale eddies is obtained using $C_{\mathrm{A}}=0.2 \mathrm{~m} / \mathrm{s}$ and $A_{\mathrm{HM}}=600 \mathrm{~m}^{2} / \mathrm{s}$.

As a result of sensitivity tests, the following set of parameters is used for all subsequent numerical experiments: grid size of $6.7 \mathrm{~km}$ ('fine grid'), barotropic and baroclinic time steps of 20 and $200 \mathrm{~s}$ respectively, and horizontal diffusion parameters $C_{\mathrm{A}}=0.2 \mathrm{~m} / \mathrm{s}$ and $A_{\mathrm{HM}}=600 \mathrm{~m}^{2} / \mathrm{s}$. 

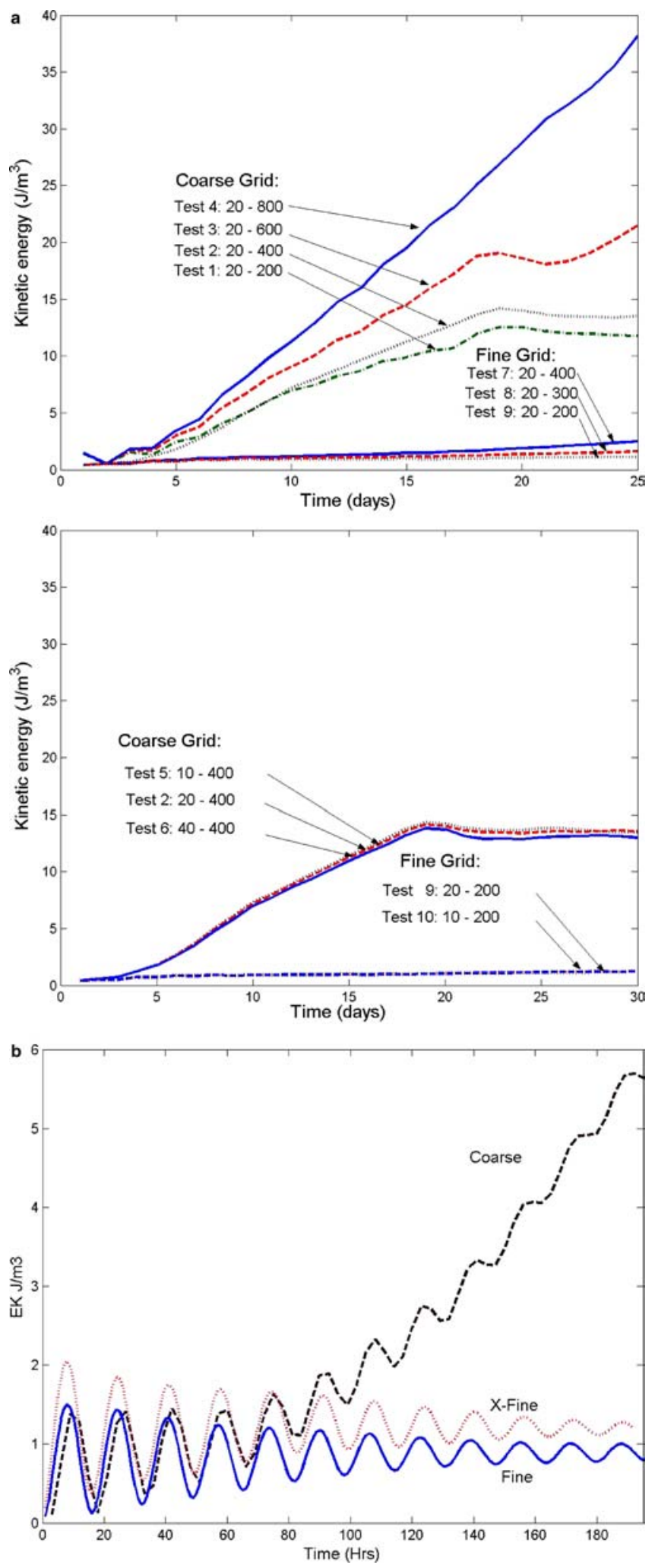

\section{Model initialisation and forcing}

The model is initialised with a three-dimensional climatologic temperature and salinity distribution for
Fig. 3 a Time series of the basin averaged total kinetic energy for a number of time steps and different horizontal grid sizes. Top panel has barotropic time step of $20 \mathrm{~s}$ with varying baroclinic time steps and bottom panel has baroclinic time step of $400 \mathrm{~s}$ with varying barotropic time steps. The figure shows result of a snapshot every $24 \mathrm{~h} \mathrm{~b}$ Basin averaged kinetic energy under different grid resolution: Coarse grid $1 / 4^{\circ}(\sim 25 \mathrm{~km})$, fine grid $1 / 14^{\circ}(\sim 6 \mathrm{~km})$ and $\mathrm{x}$-fine grid $1 / 24^{\circ}(\sim 3 \mathrm{~km})$. For the fine grid, the Mean Kinetic Energy reaches saturation after approx $127 \mathrm{~h}$, by this time the amplitude of Eddy Kinetic Energy, EKE, decays by a factor of 5

the month of May (Staneva and Stanev 1998) and zero velocities. Using the geostrophic adjustment approach, the model ran without any external forcing and allowed to relax to develop the velocity field compatible with initial density distribution. The parameters used for model adjustment (Run no. 9) are listed in Table 1. To assess when the equilibrium state is reached, the total kinetic energy of the whole basin is monitored (Fig. 3b, lower curve). Within the first few days of integration, the kinetic energy shows a strong oscillatory signal with decaying amplitude. The quasi-geostrophic adjustment is achieved within $127 \mathrm{~h}$. This time interval is long enough to achieve a state of intermediate asymptotics (Barenblatt 1996) with a nearly constant level of mean kinetic energy and significantly damped $17 \mathrm{~h}$ oscillations. On the other hand, it is short enough not to introduce significant modification to the initial temperature and salinity fields. The correlation between the modelled temperature after $127 \mathrm{~h}$ of geostrophic adjustment and the initial temperature at each grid point is plotted in Fig. 4 and gives a correlation coefficient $R^{2}$ of 0.98. Small scatter is seen in Fig.4 in the surface layer (upper end of the temperature range) and the cold intermediate layer (temperatures $7-9^{\circ}$ ), where the Rim current is the strongest. The velocity distribution obtained through the pre-initialisation stage is used together with the temperature and salinity fields to initialise the full main model simulations.

The forcing for the model includes (a) the reanalysis wind data from the National Centre for Environmental Prediction (NCEP), having $1^{\circ}$ spatial resolution and $6 \mathrm{~h}$ temporal interval [http:// wwwt.ncep.noaa.gov/]; (b) climatologic monthly heat fluxes at the sea surface, rates of evaporation and precipitation (Staneva and Stanev 1998); (c) freshwater discharge from six rivers (Jaoshvili 2002) and (d) water exchange in the Bosphorus Strait and with the Azov Sea (Altman and Kumish 1986). The three major European rivers, the Danube, Dniepr and Dniestr, discharge into the north-western area, and the Sakarya, Kizilirmak and Yesilirmak rivers discharge into the southern part of the Black Sea. These six rivers account for more than $90 \%$ of the total river discharge into the Black Sea basin. The river locations are presented in Fig. 1 and the volume of discharge and temperature included in the modelling are detailed in Table 3. The wind stress is calculated using interpolated wind data with a drag coefficient of 0.001 and 
air density of $0.00129 \mathrm{~g} / \mathrm{cm} 3$ (Yuriy Ratner, personal communication, 2001). The model is run forward from 1 May 2000 for 12 months, with the wind forcing being updated every $6 \mathrm{~h}$, and the other forcing updated every $24 \mathrm{~h}$.

\section{Results and discussion}

The purpose of this section is to analyse simulated large and mesoscale circulation at a specific season and compare where possible simulated and observed characteristics. For this reason we have selected the 60 days of late spring, from 1 May to 30 June 2000, from a 12month long simulation. As the depths of sigma-coordinate surfaces vary in the horizontal, all near surface data were interpolated, for the purpose of analysis and visualisation, to the fixed depth of $7.5 \mathrm{~m}$ which was taken as a 'representative' of true surface values.

First, we briefly discuss the ability of the model to simulate large-scale patterns of physical parameters. The distribution of currents and temperature anomalies at $7.5 \mathrm{~m}$ depth at day 19 of the numerical simulation are presented in Fig. 5 and the SST satellite image for the same day is presented in Fig. 6. The anomalies are calculated relative to a point in the centre of the sea away from the fronts. The highest temperatures in the model run are found in the south-east of the Black Sea and in the northern part of the north-western shelf and the warmest patches are located especially at the centres of anticyclones. The coldest water is in general in the areas of the shelf break all around the basin except for the south-eastern part of the basin. Simulated surface temperature pattern (Fig.5) compares favourably with satellite imagery in Fig.6.

Modelled salinity distribution is generally coincident with what is obtained from in situ observations (Blatov et al. 1984). The fresher water at $7.5 \mathrm{~m}$ depth (not shown) is present in the north-western area resulting from the major river discharges. Further away from the coast, there is a steep salinity gradient towards the deep sea. The saltier water is located mainly in the central part of the basin and the maximum salinity values are found within patches corresponding to the cyclonic gyres. However, in contrast to the surface temperature fields, the detailed comparison of observed and modelled salinity fields is limited as the snapshots of salinity patterns from in situ observations are not available.

An example of vertical distribution of temperature and salinity is shown on a longitudinal transect, which crosses both wide shelf in the North West part of the sea and the deep basin, and shows the ability of the model to reproduce major features of the vertical structure of water masses in the Black sea, Fig.7. The vertical distribution of temperature (Fig. 7, left panel) shows the surface mixed layer reaching about $15-30 \mathrm{~m}$ depth. The thermocline is located below the mixed layer and it is characterised by an abrupt temperature gradient. The thickness of the thermocline ranges approximately 25
$50 \mathrm{~m}$. The Cold Intermediate Layer (CIL), is below the thermocline and is located approximately between 50 and $125 \mathrm{~m}$ depth over the central and eastern part; however, it goes deeper in the western part, below the core of the Rim Current. Below the CIL, the temperature increases with a much smoother gradient than the one above it. The vertical salinity field shows that the variations are confined to the upper layer. The modelled structure of the water mass is in good agreement with reported observations (Blatov et al. 1984; Ozsoy and Unluata 1997).

The simulated circulation pattern at the sea surface includes the basin wide cyclonic current, Rim Current, flowing around the basin, the sub-basin cyclonic gyres in the central part of the sea and a number of eddies and meanders off the Rim Current. The Rim Current is approximately $40-60 \mathrm{~km}$ wide, the current speed at its core varies typically between 25 and $35 \mathrm{~cm} / \mathrm{s}$ and reaches a maximum velocity of up to $50 \mathrm{~cm} / \mathrm{s}$ in places where it merges with an anticyclonic eddy. Simulated parameters of the Rim Current coincide with observations (Blatov et al. 1984; Ozsoy and Unluata 1997; Korotaev et al. 2003).

The combined map of surface currents and temperature (Fig 5) shows the Rim Current advecting warmer water to the north-west in the eastern coast and to the west with its northern branch. It also shows the presence of gyres (e.g. warmer patch in the south-western part of the central basin) and mesoscale features (e.g. eddies and fingers). The geographical distribution, size and shape of the modelled mesoscale currents agree with the satellite image analysis (Fig. 6). However, the absolute values of the modelled temperature at the sea surface are lower that those obtained from satellite images. It is thought that the assimilation of solar penetration depth in the model instead of using the exponential decay, as well as the use of three hour winds and heat fluxes instead of climatology, would improve the accuracy of the modelled temperatures.

The number of eddies and sub-gyres in the model run ranges from 5 to more than 15 at times. Some of the larger eddies (sub-gyres) have a permanent or semipermament nature and are linked to bottom topography. These eddies (e.g. the eastern and western sub-basin gyres, Kizilimak or Batumi eddies, see more details below and in Table 4) are seen in the climatic hydrophysical data (Blatov et al.1984) and they appear quickly in the model runs as the model is initialised with climatic temperature and salinity fields. The circulation pattern in the beginning of the run shortly after geostrophic adjustment of the currents (day 2) represents climatic signature of both basin-scale and mesoscale activity and is shown in Fig. 8 and includes: (1) the Rim Current which meanders on its southern side, (2) four sub-basin gyres located in the central part of the basin: in the south-west, south of Crimean Peninsula, in the north-east and in the south-east, (3) coastal anticyclones and (4) three mesoscale eddies in the north-western continental shelf. 
Fig. 4 The regression curve of the initial temperature against temperature after geostrophic adjustment. Dots correspond to each grid node of the domain

Table 3 Lateral water exchange used for modelling

Volume discharges are positive for input of water into the Black Sea

Fig. 5 Mesoscale structures as present in the model at day 19 (19 May 2000). Numbers correspond to Table 4 and the dark lines show the location of vertical transects in Fig. 9. Anomalies calculated relative to the area in the centre of the sea

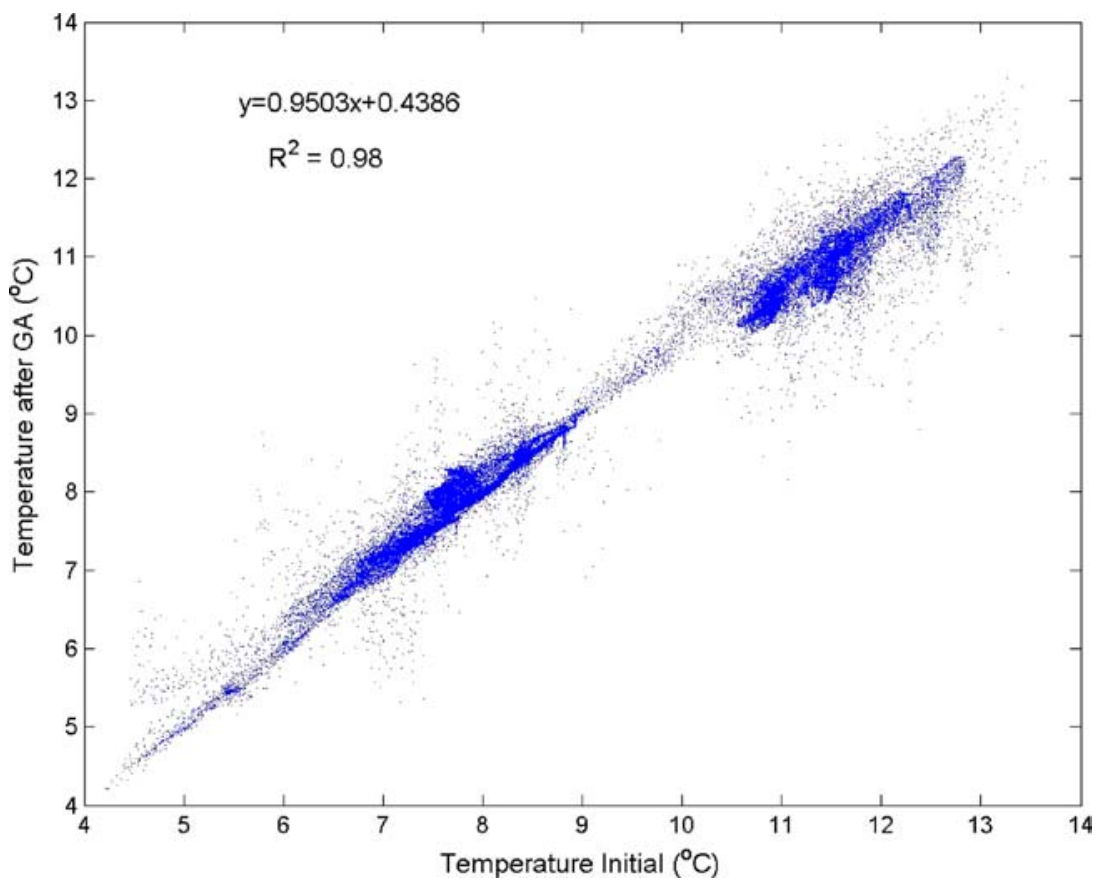

\begin{tabular}{|c|c|c|c|c|}
\hline \multirow{2}{*}{$\begin{array}{l}\text { River } \\
\text { Id. }\end{array}$} & \multirow{2}{*}{$\begin{array}{l}\text { Volume discharge } \\
\text { Name }\end{array}$} & \multicolumn{3}{|c|}{ Temperature $\left({ }^{\circ} \mathrm{C}\right)$} \\
\hline & & $\left(\mathrm{m}^{3} / \mathrm{s}\right)$ & May & June \\
\hline 1 & Dniepr & $1,398.5$ & 11.9 & 18.2 \\
\hline 2 & Dnestr & 292.6 & 13.2 & 19.1 \\
\hline 3 & Danube & 6,430 & 13.7 & 19.6 \\
\hline 4 & Sakarya & 180 & 14.1 & 19.0 \\
\hline 5 & Kizilirmak & 189.6 & 13.2 & 17.4 \\
\hline 6 & Yesilirmak & 170.4 & 13.4 & 17.4 \\
\hline A & Bosphorus & $-6,269.2$ & 10.8 & 17.5 \\
\hline B & Azov & 546.6 & 14.0 & 20.1 \\
\hline
\end{tabular}

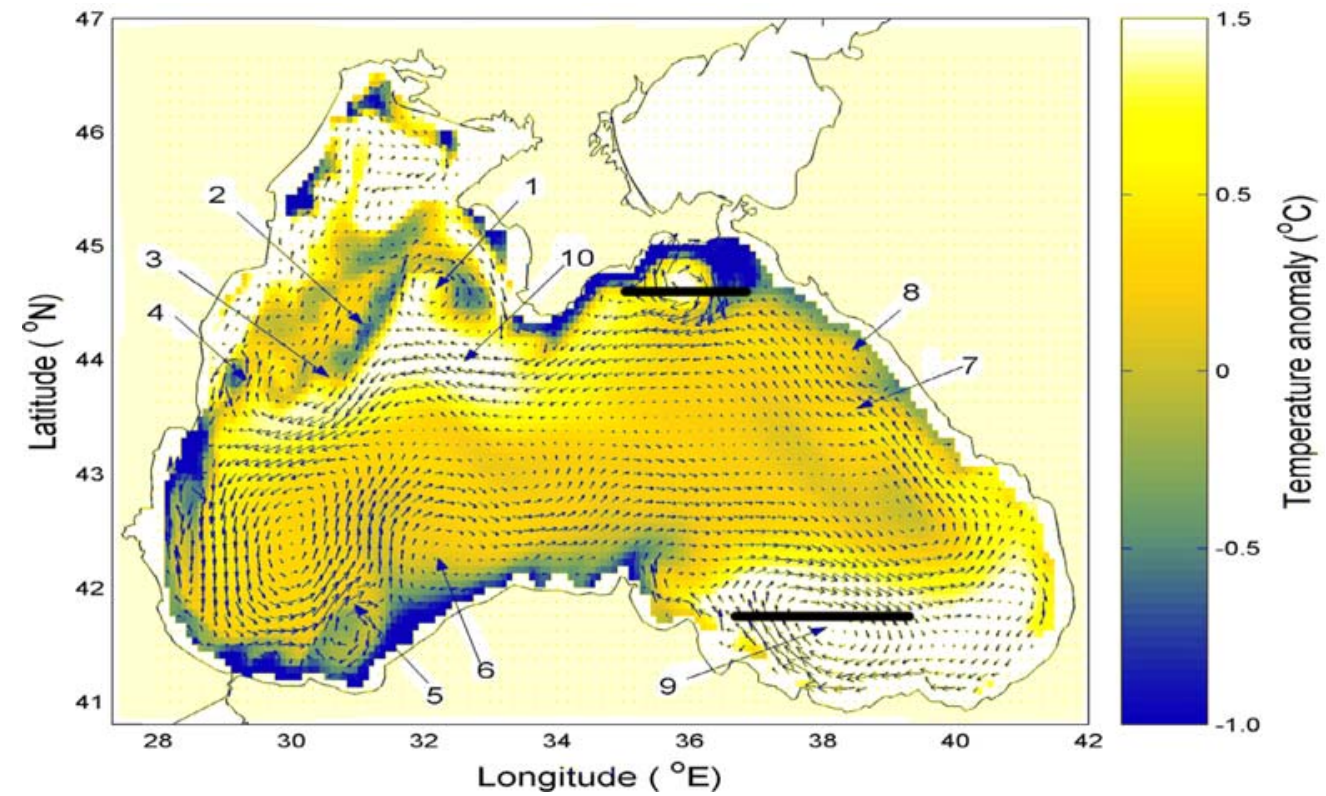


Fig. 6 Temperature anomaly from the satellite image of the 19 May 2000 to show the mesoscale features which are present in the model output at day 19 of the simulation. Anomalies calculated relative to the area in the centre of the sea

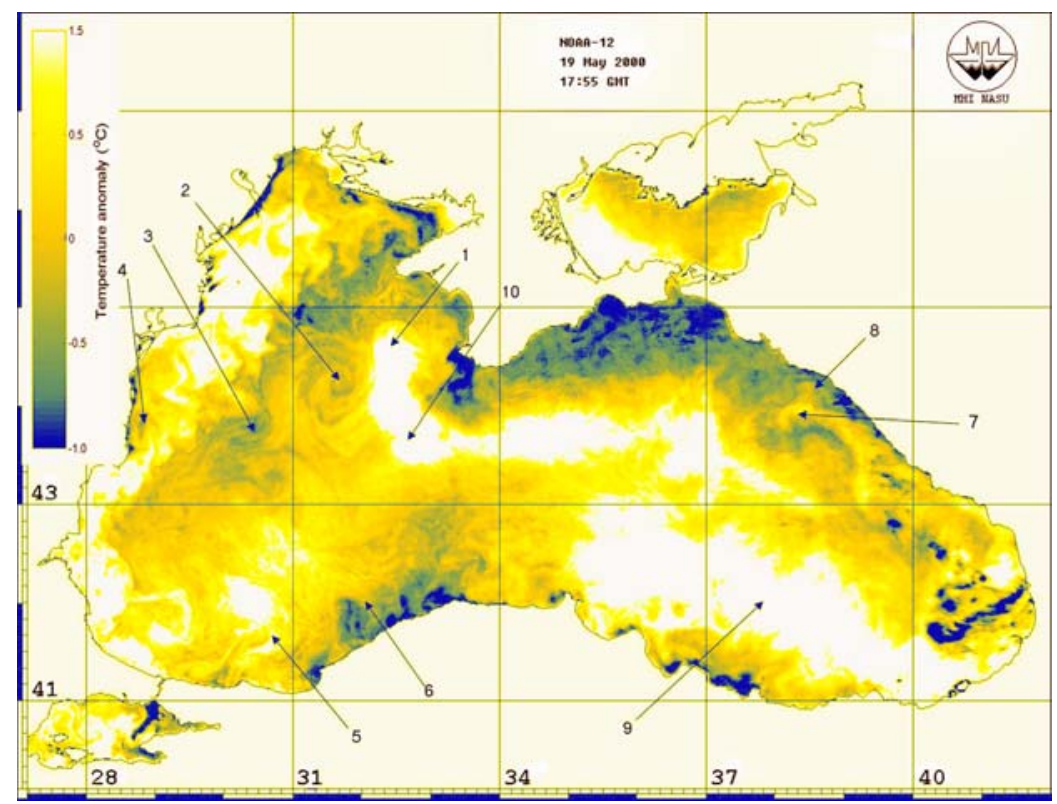

Temperature transect $\left({ }^{\circ} \mathrm{C}\right)$ Lat $=44^{\circ} \mathrm{N}$; Plot:50
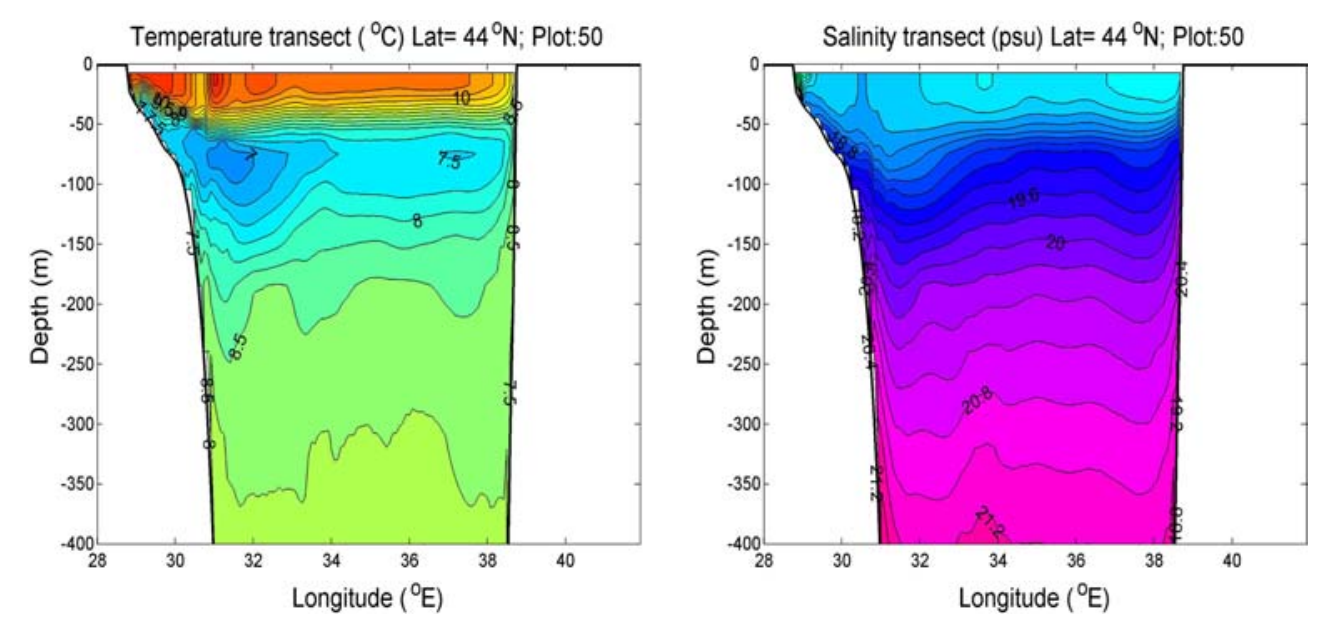

Fig. 7 Vertical transects of temperature (left panel) and salinity (right panel) from a zonal cross-section at latitude $44^{\circ} \mathrm{N}$ at day 35 of the run ( 5 June 2000). Three main temperature structures are clearly seen: the surface mixed layer; the upper thermocline; and the Cold Intermediate Layer
Other eddies develop and dissipate occasionally, many of them branch off the basin-scale Rim Current (Figs. 5 and 6 . These eddies are not seen in the climatic distribution and are formed dynamically through nonlinear interaction of currents and wind forcing. The size of eddies varies from 10 to more than $100 \mathrm{~km}$ and their lifetimes vary from days to months. The predominant mesoscale eddies present both in the simulations and observations (Ozsoy and Unluata 1997) are listed in Table 4.

The model simulations also reveal near-shore mesoscale eddies, which are located between the core of the Rim Current and the coastline. Most frequently these eddies are anticyclones. These results are consistent with recent observations which show, both in satellite imagery and in situ surveys, that the Rim Current is often accompanied by a series of localised recurrent nearshore anticyclones (Zatsepin et al. 2003). Most of these eddies are not steady but move cyclonically around the basin of the Black Sea with the large-scale circulation and interact actively with the current jet and adjacent eddies (Sur et al. 1997; Ginzburg et al.2002).

Visual comparison with satellite imagery shows that most of the mesoscale structures, which are seen in remotely sensed images, are properly simulated by the model regarding their size, shape and evolution. These structures (numbered as follows in Figs. 5 and 6) include (a) mesoscale eddies such as Sevastopol (1), Kali-Akra (2), Bosphorus (at the west of the basin), Sakarya (5), Crimea (at the east of Crimean Peninsula), Kizilirmak (9) and Caucasus (8) eddies; (b) coastal upwellings (near the Crimean Peninsula and the southern coast); (c) cold water 
Table 4 Mesoscale eddies present in the modelling

\begin{tabular}{lllll}
\hline No. & Mesoscale eddies & Location & Velocity(m/s) & Depth of penetration $^{1}$ \\
\hline 1 & Sevastopol & West of Crimean peninsula & $0.10-0.20$ & $\sim 400 \mathrm{~m}$ \\
2 & Kali-Akra & West of Sevastopol eddy & $0.10-0.25$ & $\sim 130$ \\
& Bosphorus & South-western coast & $0.15-0.35$ & $\sim 200$ \\
5 & Sakarya & South coast at $\sim 31^{\circ} \mathrm{E}$ & $0.15-0.25$ & $>800 \mathrm{~m}$ \\
& Crimea & East of Crimean peninsula & $0.10-0.40$ & $\sim 350 \mathrm{~m}$ \\
8 & Sinop & South coast at $\sim 36^{\circ} \mathrm{E}$ & $0.10-0.20$ & $\sim 200 \mathrm{~m}$ \\
9 & Caucasus & North-eastern coast & $0.10-0.15$ & $\sim 100 \mathrm{~m}$ \\
& Kizilirmak & South coast $\sim 38^{\circ} \mathrm{E}$ & $0.10-0.30$ & $\sim 200 \mathrm{~m}$ \\
& Batumi & South-eastern coast & $0.10-0.18$ & $\sim 400 \mathrm{~m}$ \\
\hline
\end{tabular}

${ }^{1}$ Vertical penetration of the eddies at day 40 of the simulation (10 June 2000)

fingers (associated with anticyclones e.g. with the Sakarya, Sevastopol and Crimean eddies); (d) patches of warm water transported by the Rim Current jet (10 and 7), etc.

The depth of penetrating of eddies in the Black Sea is a controversial issue. Some studies argue that currents in the Black Sea do not go deeper than 300-400 m (e.g. Blatov et al. 1984), others suggest that they may be seen significantly deeper, particularly at the shelf break and may even generate the counter currents at depth (Korotaev et al. 2003 and references therein). In our model studies, the depth of penetration of eddies varies typically from tens of metres to more than $400 \mathrm{~m}$ depth, see, for example, the vertical cross-sections of the horizontal $v$ component of the velocity of the Crimean and Kizilirmak anticyclones in Fig. 9. The simulations also show that near bottom counter currents could exist at the continental rise at the depth down to $700 \mathrm{~m}$ (Fig. 9), in support of recent observational results (Korotaev 2005)

As to the individual mesoscale eddies, the model simulations compare favourably with the analysis of long-term series of satellite sea surface temperature imagery (Ginzburg et al. 2000, 2002; Zatsepin et al. 2002, 2003). The model correctly represents the main parameters of the eddies, which appear recurrently in observations. More detailed examples of those modelled features of eddies that are coincident with observations are shown below.

Our modelling results show the formation of the Sevastopol eddy (No. 1 in Fig. 10) at the west of the Crimean Peninsula in the north-western part of the sea. It remains nearly stationary and grows in strength and size for about 1.5 weeks, then its size decreases and the eddy moves to the west where it stays for another month and then dissipates by merging with the Rim Current.

During the simulation, several smaller cyclones and anticyclones were formed around the Sevastopol eddy, some of them propagating to the south west in the direction of the Rim Current (No. 2 in Fig. 10).

The Bosphorus eddy (No. 3 in Fig. 10) begins forming approximately after 1 week of the simulation and from then on it is present throughout the period of modelling. However, its size, strength and shape change
Fig. 8 Circulation features present at the model after the geostrophic adjustment: 1 Rim Current, 2 sub-basin gyres, 3 coastal anticyclones, 4 mesoscale eddies in the northwestern continental shelf

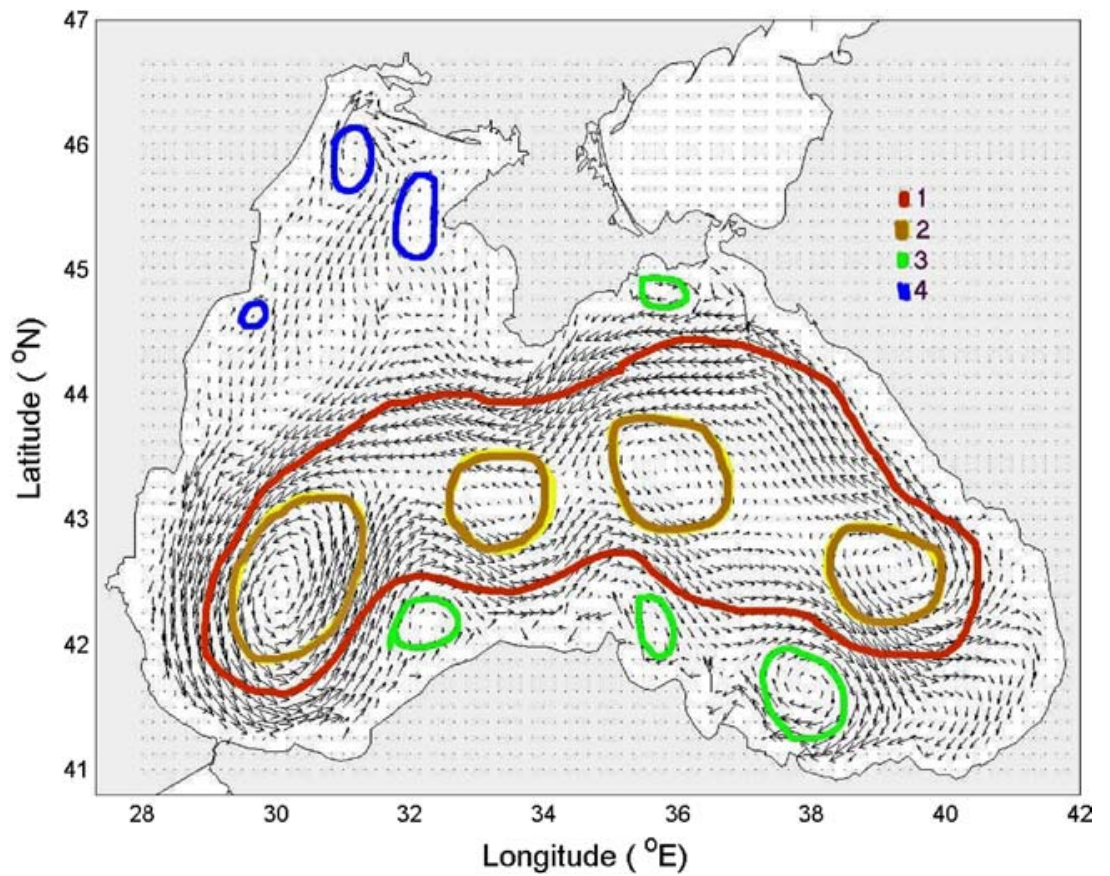


Fig. 9 Vertical cross-sections of the horizontal velocity structure (v-component, $\mathrm{m} / \mathrm{s}$ ) of the Crimean (top panel) and Kizilirmak (bottom panel) anticyclones during the 10th of June 2000 . Locations of the transects are shown in Fig. 5
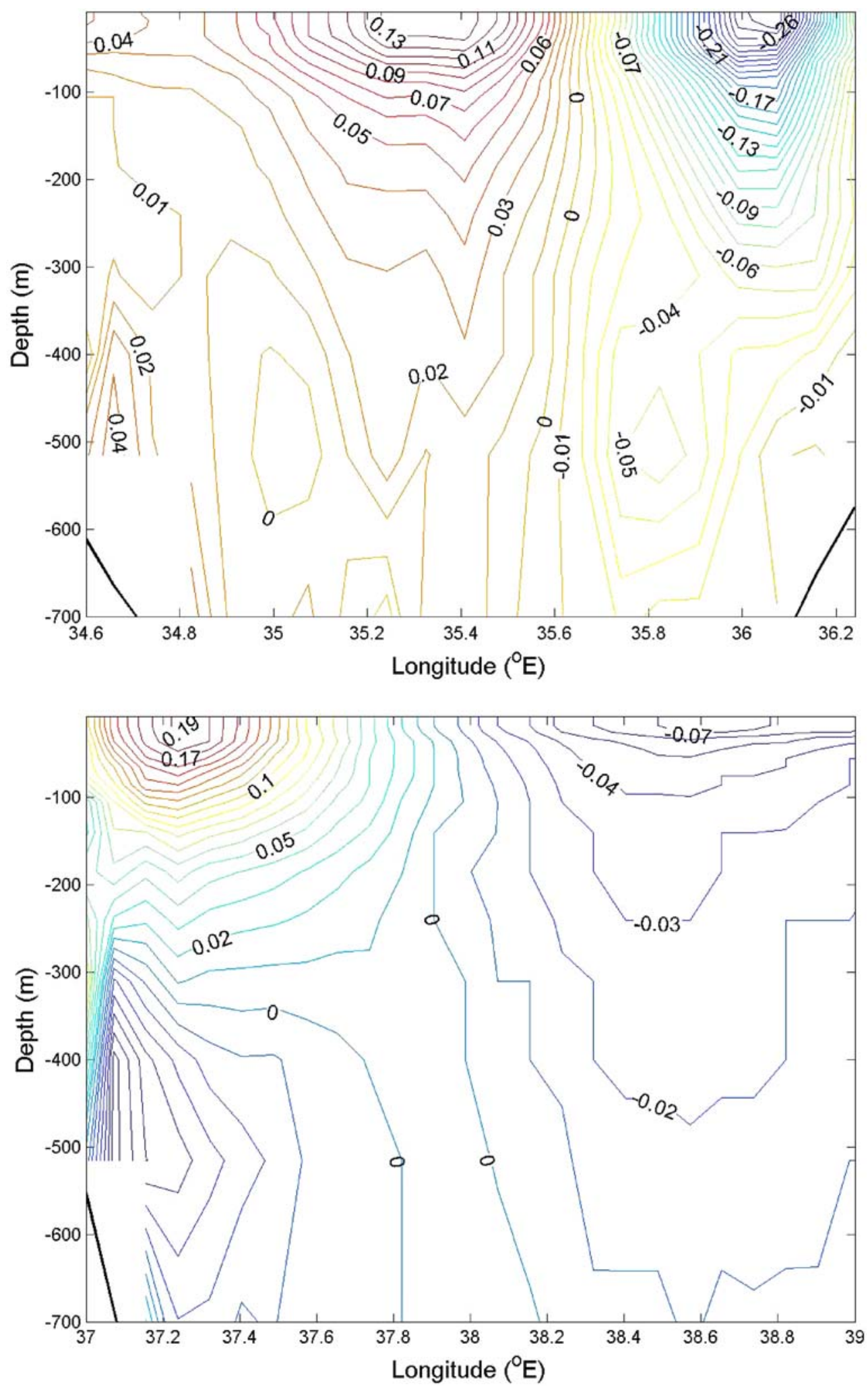

within the period of 2 months. In the first weeks of simulation, it has an elliptical shape and is extended along the coast. Then, it becomes more rounded and reduces its orbital velocity. Towards the end of the run, it again becomes larger and elongated and attaches itself closer to the coast.
The Sakarya anticyclone (No. 4 in Fig. 10) has a different behaviour, it is formed three times during the simulation, each time it grows and then dissipates, and shortly afterwards it is formed again.

The Kizilirmak anticyclone (No. 1 in Fig. 11) is very well defined from the initialisation stage and remains 
Fig. 10 Mesoscale eddies present in the western part of the Black Sea at day 30 of the simulation: 1 Sevastopol, 2 Kali-Akra and associated eddies, 3 Bosphorus and 4 Sakarya anticyclones. Arrows indicate surface currents and shading shows temperature anomalies

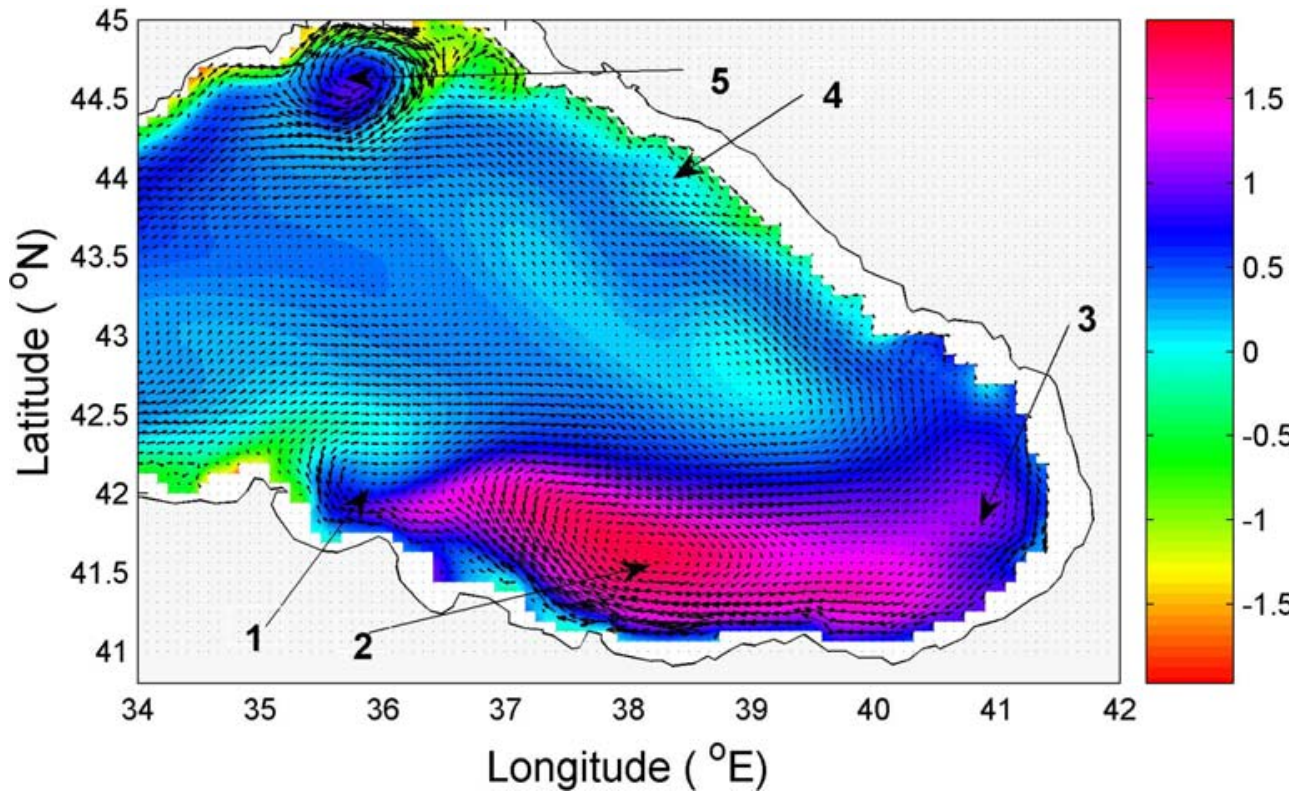

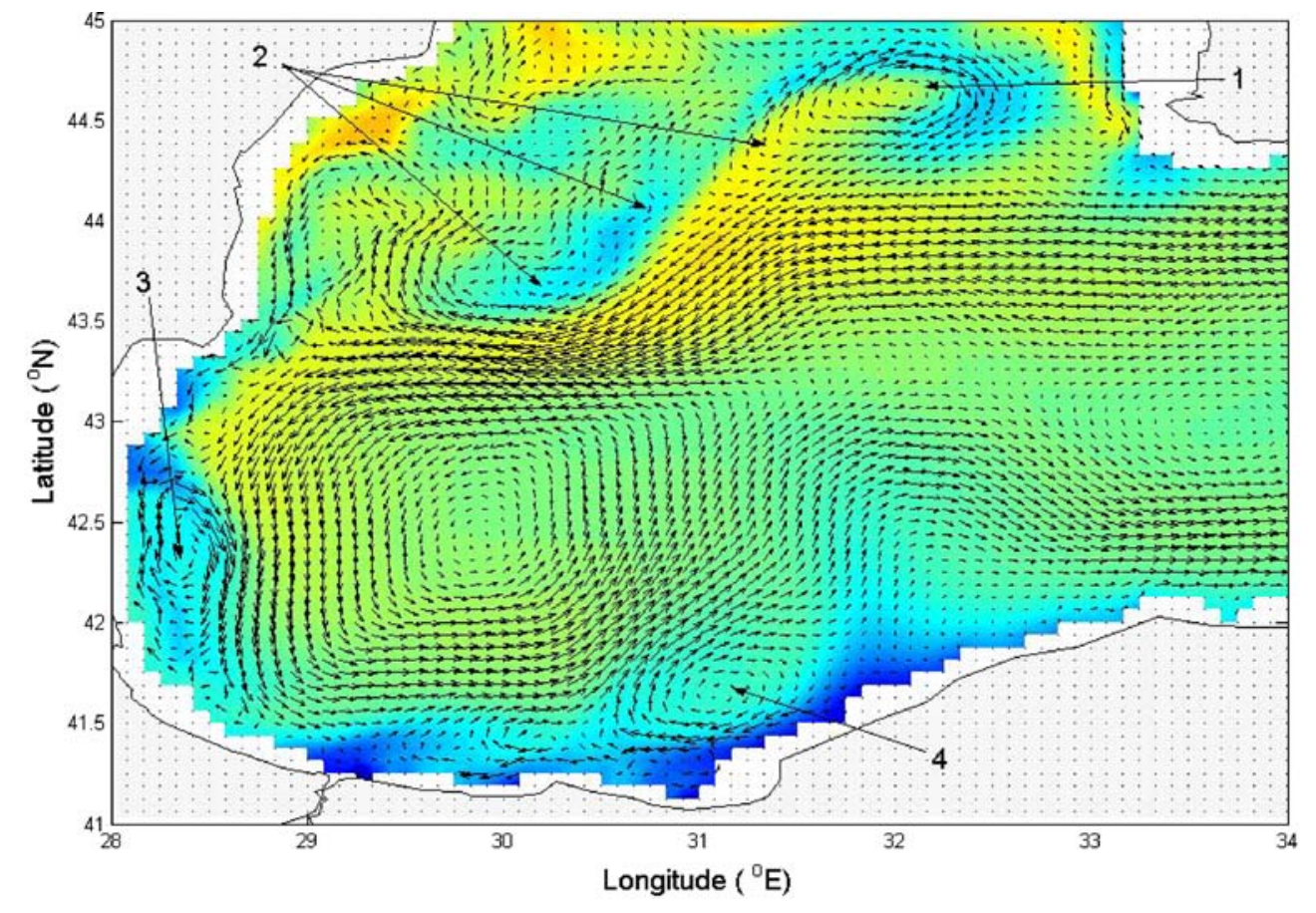

.
Fig. 11 Mesoscale eddies present in the eastern part of the Black Sea at day 25 of the simulation: 1 and 2 anticylones at the southern coast, possibly the Kizilirmak and Sinop anticylones, 3 location of the Batumi eddy, 4 Caucasus and 5 Crimean anticyclones. Arrows indicate surface currents and shading shows temperature anomalies 
when the Rim Current flows further from the coast or is meandering away from the coast, the Caucasus eddy is rounder and bigger.

To the east of the Crimean peninsula, there is at least one well-defined anticyclone (the Crimean Anticyclone) over the whole period of simulation, (No. 5 in Fig. 11). During shorter periods of time, this anticyclone has associated smaller eddies, mainly anticyclones, on either sides.

While the model gives a good approximation of the real pattern of mesoscale activity and main parameters of individual eddies, the timing of eddy formation and the exact locations of non-stationary moving eddies are subject to some phase lag. This is probably due to the fact that the model is initialised with monthly averaged climatic data, while the time scale for mesoscale variability is measured in weeks.

\section{Conclusions}

A three-dimensional structure of mesoscale circulation in the Black sea is simulated using the POLCOMS Modelling System. The sensitivity tests reveal that the model is mostly sensitive to the grid size and the baroclinic time step and much less sensitive to other computational parameters including the barotropic time step (within a certain range). Three numerical grids are examined, the $x$-fine $(3.2 \mathrm{~km}$ resolution), fine $(6.7 \mathrm{~km})$ and the coarse one $(25 \mathrm{~km})$. It is found that the coarse grid significantly overestimates the energy of the currents and is not adequate even for the study of basinscale circulation. The $x$-fine grid, on the other hand, does not give significant advantages compared to the fine grid for the study of mesoscale circulation, and the latter is used for the bulk of simulations. The most adequate parameters are chosen from the sensitivity study and used to model both the basin-scale circulation and the day-to-day variability of mesoscale currents for the months of May and June of 2000.

The comparison of the model output against the satellite imagery and in situ measurements shows that the model adequately reproduces the general circulation and many mesoscale features including cyclonic and anticyclonic eddies, jets and filaments in different parts of the Black Sea. The model gives realistic geographical distribution and parameters of the mesoscale currents, such as size, shape and evolution of the eddies. It also gives correct representation of the vertical structure of water masses, such as the CIL and the pycnocline.

The model proved to be suitable for scenario based simulation of mesoscale currents in the Black Sea.

Acknowledgements The authors gratefully acknowledge Joanna Staneva for providing monthly climatic data for temperature and salinity, heat fluxes, evaporation and precipitation. We kindly acknowledge Yury Ratner for providing interpolated wind data and Sergey Stanichny and Dmitry Soloviev for providing processed satellite SST images. We are thankful to Vladimir Ivanov for helpful discussions. This research was supported by Consejo Nacional de
Ciencia y Tecnología (CONACYT, Mexico)-Scholarship no. 153397 (C. Enriquez), the European Union grants, INTAS - 01-460, INTAS -03-51-4620; and the RFBR grant 05-05-64686

\section{References}

Altman EN, Kumish NI (1986) Interannual and seasonal variability of the Black Sea fresh water balance, Trudy Gos. Okeanograph Instituta $145 \mathrm{p}$

Arakawa A (1972) Design of the UCLA general circulation model. Rep 7, University of California

Barenblatt GI (1996) Scaling, self-similarity and intermediate asymptotics. Cambridge University Press, Cambridge $386 \mathrm{p}$

Besiktepe ST, Lozano CJ, Robinson AR (2001) On the summer mesoscale variability of the Black Sea. J Mar Res 59:475-515

Blatov AS, Bulgatov NP, Ivanov VA, Kosarev AN, Tuzhilkin VS (1984) Variability of hydrophysical fields of the Black Sea. Gidrometeoizdaft, St. Petersburg, 240 p

Blumberg AF, Mellor GL (1987) A description of a three dimensional coastal ocean model. Heaps NS [4], 1-16. Washington, DC, AGU. Three-Dimensional Coastal Ocean Models, Coastal and Estuarine Studies $16 \mathrm{p}$

Burchard H, Bolding K (2002) GETM: a general estuarine transport model. Scientific documentation. Technical Report EUR 20253 EN, European Commission

Ginzburg AI, Kostianoi AG, Krivosheya VG, Nezlin NP, Soloviev DM, Stanichnyi SV, Yakubenko VG (2000) Peculiarities of the water dynamics and chlorophyll a distribution in the northeastern part of the Black Sea in Autumn 1997. Oceanology 40:316-328

Ginzburg AI, Kostianoy AG, Nezlin NP, Soloviev DM, Stanichny SV (2002) Anticyclonic eddies in the northwestern Black Sea. J Mar Syst 32:91-106

Haidvogel D, Arango HG, Hedstrom K, Beckmann A, MalanotteRizzoli P, Shchepetkin AF (2000) Model evaluation experiments in the North Atlantic Basin: simulations in nonlinear terrain-following coordinates. Dynamics Atmos Oceans $32: 239-281$

Holt JT, James ID (2001) An s coordinate density evolving model of the northwest European continental shelf-1, Model description and density structure. J Geophys Res Oceans 106:1401514034

Huthnance JM (1995) Circulation, exchange and water masses at the ocean margin: The role of physical processes at the shelf edge. Progress Oceanogr 35:353-431

James ID (1986) A front-resolving sigma coordinate model with a simple hybrid advection scheme. Appl Math Model 10:8792

James ID (1996) Advection schemes for shelf sea models. J Mar Syst 8:237-254

Jaoshvili Sh (2002) The rivers of the Black Sea. Rep 71, 1-58, European Environment Agency $58 \mathrm{p}$

Kantha LH, Clayson CA (2000) Numerical models of oceans and oceanic processes. Academic, $940 \mathrm{p}$

Knipovich NM (1932) The hydrological investigations in the Black Sea. Rep 10, 1-274, Trudy Azova-Dhernomorskoy Nauchnopromyslovoy Ekspeditsii 274 p

Korotaev GK (2005) Black sea water circulation: synthesis of the results. International conference on sustainable development of the Mediterranean and Black Sea environment . Thessaloniki, Greece http://www.iasonnet.gr/past_conf/abstracts/korotaev.html

Korotaev G, Oguz T, Nikiforov A, Koblinsky C (2003) Seasonal, interannual, and mesoscale variability of the Black Sea upper layer circulation derived from altimeter data. J Geophys Res Oceans 108, art 3122

Mee LD (2001) Eutrophication in the Black Sea and a basin-wide approach to its control. In: Bodungen B, Turner RK (eds) Science and integrated coastal management. Dahlem University Press, pp 71-92 
Mellor GL, Ezer T, Oey LY (1994) The pressure-gradient conundrum of sigma coordinate ocean models. J Atmos and Oceanic Technol 11:1126-1134

NOAA (1988) Digital relief of the surface of the Earth. NOAA. National Geophysical Data Center, Boulder, CO

Oguz T, Besiktepe S (1999) Observations on the Rim Current structure, CIW formation and transport in the western Black Sea. Deep-Sea Research Part I-Oceanographic Research Papers 46:1733-1753

Oguz T, Malanotte-Rizzoli P, Aubrey D (1995) Wind and thermohaline circulation of the Black Sea driven by yearly mean climatological forcing. J Geophys Res Oceans 100:6845-6863

Ozsoy E, Unluata U (1997) Oceanography of the Black Sea: a review of some recent results. Earth-Sci Rev 42:231-272

Proctor R, Holt JT, Allen JI, Blackford J (2003) Nutrient fluxes and budgets for the North West European Shelf from a threedimensional model. Sci Total Environ 314:769-785

Shapiro GI, Akivis TM, Pykhov NV, Antsyferov SM (2000) Transport of fine sediment with mesoscale currents in the shelfslope zone of the sea. Oceanology 40:305-311

Shchepetkin AF, McWilliams JC (2003) A method for computing horizontal pressure-gradient force in an oceanic model with a nonaligned vertical coordinate. J Geophys Res Oceans 108 art3090

Song Y, Haidvogel D (1994) A semi-implicit ocean circulation model using a generalized topography-following coordinate system. J Geophys Res Oceans 115:228-244

Souza AJ, James ID (1996) A two-dimensional (x-z) model of tidal straining in the rhine ROFI. Cont Shelf Res 16:949-966

Stanev EV, Beckers JM (1999) Barotropic and baroclinic oscillations in strongly stratified ocean basins: numerical study of the Black Sea. J Mar Syst 19:65-112

Stanev EV, Rachev NH (1999) Numerical study on the planetary Rossby modes in the Black Sea. J Mar Syst 21:283-306

Stanev EV, Staneva JV (2000) The impact of the baroclinic eddies and basin oscillations on the transitions between different quasistable states of the Black Sea circulation. J Mar Systems 24:326

Stanev EV, Staneva JV (2001) The sensitivity of the heat exchange at sea surface to meso and sub-basin-scale eddies: model study for the Black Sea. Dynam Atmos Oceans 33:163-189
Stanev EV, Roussenov VM, Rachev NH, Staneva JV (1995) Sea response to atmospheric variability: model study for the Black Sea. J Mar Syst 6:241-267

Stanev E, Staneva JV, Bullister JL, Murray JW (2005) Ventilation of the Black Sea pycnocline. Parameterization of convection, numerical simulations and validations against observed chlorofluorocarbon data. Deep-Sea Research Part I-Oceanographic Research Papers, in press

Staneva JV, Stanev E (1998) Oceanic response to atmospheric forcing derived from different climatic data sets. Intercomparison study for the Black Sea. Oceanologica Acta 21:393-417

Staneva JV, Dietrich DE, Stanev EV, Bowman MJ (2001) Rim current and coastal eddy mechanisms in an eddy-resolving Black Sea general circulation model. J Mar Syst 31:137-157

Sur HI, Ilyin YP (1997) Evolution of satellite derived mesoscale thermal patterns in the Black Sea. Progress Oceanogr 39:109-151

Vostokov SV, Lisitsyn BE, Konovalov BV, Soloviev DM, Gagarin VI (2002) Mesoscale variability of chlorophyll "a" concentration, particulate organic matter content and spectral index of light absorption by phytoplankton in the upper layer of North Eastern part of the Black Sea. In: Zatsepin AG, Flint MV (eds) Multidisciplinary investigations of the Northeast part of the Black Sea. pp 235-247, Moscow, Nauka, 476 p

Wilson C, Williams RG (2004) Why are eddy fluxes of potential vorticity difficult to parameterize? J Phys Oceanogr 34:142-155

Zatsepin AG, Ginzburg AI, Kostyanoy AG, Kremenetskiy VV, Krivosheya VG, Poyarkov SG, Ratner YB, Skirta AY, Soloviev DM, Stanichny SV, Stroganov OY, Sheremet NA, Yakubenko VG (2002) Variability of water dynamics in the northeastern Black Sea and its effect on the water exchange between the near-shore zone and open basin. Oceanology 42:S1-S15

Zatsepin AG, Ginzburg AI, Kostianoy AG, Kremenetskiy VV, Krivosheya VG, Stanichny SV, Poulain PM (2003) Observations of Black Sea mesoscale eddies and associated horizontal mixing. J Geophys Res Oceans 108, art-3246

Zhurbas VM, Zatsepin AG, Grigor'eva YV, Eremeev VN, Kremenetsky VV, Motyzhev SV, Poyarkov SG, Poulain PM, Stanichny SV, Soloviev DM (2004) Water circulation and characteristics of currents of different scales in the upper layer of the Black Sea from drifter data. Oceanology 44:30-43 